\title{
A specialist-generalist classification of the arable flora and its response to changes in agricultural practices
}

\author{
Guillaume Fried ${ }^{1,2}$, Sandrine Petit ${ }^{1}$, Xavier Reboud $^{1 *}$
}

\begin{abstract}
Background: Theory in ecology points out the potential link between the degree of specialisation of organisms and their responses to disturbances and suggests that this could be a key element for understanding the assembly of communities. We evaluated this question for the arable weed flora as this group has scarcely been the focus of ecological studies so far and because weeds are restricted to habitats characterised by very high degrees of disturbance. As such, weeds offer a case study to ask how specialization relates to abundance and distribution of species in relation to the varying disturbance regimes occurring in arable crops.

Results: We used data derived from an extensive national monitoring network of approximately 700 arable fields scattered across France to quantify the degree of specialisation of 152 weed species using six different ecological methods. We then explored the impact of the level of disturbance occurring in arable fields by comparing the degree of specialisation of weed communities in contrasting field situations.

The classification of species as specialist or generalist was consistent between different ecological indices. When applied on a large-scale data set across France, this classification highlighted that monoculture harbour significantly more specialists than crop rotations, suggesting that crop rotation increases abundance of generalist species rather than sets of species that are each specialised to the individual crop types grown in the rotation. Applied to a diachronic dataset, the classification also shows that the proportion of specialist weed species has significantly decreased in cultivated fields over the last 30 years which suggests a biotic homogenization of agricultural landscapes.

Conclusions: This study shows that the concept of generalist/specialist species is particularly relevant to understand the effect of anthropogenic disturbances on the evolution of plant community composition and that ecological theories developed in stable environments are valid in highly disturbed environments such as agroecosystems. The approach developed here to classify arable weeds according to the breadth of their ecological niche is robust and applicable to a wide range of organisms. It is also sensitive to disturbance regime and we show here that recent changes in agricultural practices, i.e. increased levels of disturbance have favoured the most generalist species, hence leading to biotic homogenisation in arable landscapes.
\end{abstract}

\section{Background}

The concept of ecological niche as a hypothetical multidimensional space [1] has boosted the exploration of niche properties [2-4] and has enabled generalist and specialist species to be distinguished according to their respective niche breadth. Theoretical studies have tried to evaluate the origins and/or the consequences of niche-

\footnotetext{
* Correspondence: reboud@dijon.inra.fr

${ }^{1}$ INRA, UMR1210 Biologie et Gestion des Adventices, F-21000 Dijon, France Full list of author information is available at the end of the article
}

breadth differences among species. The "jack-of-alltrades is master of none" hypothesis states that the existence of generalist versus specialist species is the result of an evolutionary trade-off between the ability of species to use an extended range of resources and their capacity to exploit each one with a level of performance above those of competing species [5-8]. This trade-off has been associated with several life-history traits: generalist species are supposed to maintain higher dispersal abilities $[9,10]$ and to cope more easily with environmental stochasticity
C Biomed Central

() 2010 Fried et al; licensee BioMed Central Ltd. This is an Open Access article distributed under the terms of the Creative Commons Attribution License (http://creativecommons.org/licenses/by/2.0), which permits unrestricted use, distribution, and reproduction in any medium, provided the original work is properly cited. 
[11] while, conversely, specialists would be strongly shaped by intra-specific competition [12]. The generalistspecialist concept could thus be appropriate to find community assembly rules [13], in particular in habitats where communities are subjected to varying levels of disturbance. The distinction between generalist and specialist species can pinpoint general mechanisms of species filtering, similarly to approaches using species traits rather than the species themselves. Indeed, several authors have recently focused on the processes leading to the replacement of many specialist species by a few generalist species that take place in diverse phylogenetic groups such as fish [14], bird [15] or plant assemblages [16]. In parallel to species extinction, this so called 'biotic homogenization' process would characterize the next biodiversity crisis [17].

The weed communities of arable land provide an interesting model for exploring the generalist/specialist concept because the arable field habitat is characterized by an intense disturbance regime and by varying ecological conditions, both within a year (because of management practices) and across years (because of crop rotation). Compared to other vascular plants occurring in more stable habitats, one would expect arable weeds to be generalist species. Indeed, it has been hypothesized that "under a constant environment or slow environmental changes, inter-specific competition involves local processes that favour specialist species at the expense of generalist species, while under moderate to high rates of environmental change, local population dynamics increasingly favour high immigration rates of the generalist over the local competitive ability of the specialist" [18]. However, arable fields can also be viewed as a particular habitat harbouring a set of specialized species (i.e. arable weeds) adapted to frequent but also specific disturbances. Within a year, agricultural practices can be perceived as highly specialized with the single aim of favouring a particular species, i.e. the crop, so that all species in the seed bank sharing the same requirements might well find regularly optimal conditions for completing their life cycle. Large differences between habitat breadth of weed species are observed with some species confined to arable fields in Western Europe (e.g., weeds of winter cereal fields: Agrostemma githago, Bupleurum rotundifolium, etc.) while others are able to grow both in crops and in other less disturbed habitats (e.g., Galium aparine, Lapsana communis). Even within arable fields, differences can be observed in niche position and breadth between weeds that are specialized to a particular crop type or to particular soil conditions, and weeds that are present almost everywhere $[19,20]$. Finally, even if arable fields are characterized by stochastic conditions, a specialized species could persist temporally, for example, with dormant diaspores that would wait for optimal environmental conditions e.g., high relative summer air humidity for arable bryophyte species [21] or each time a favourable crop occurs in the rotation [22]. Therefore, even though most agroecosystems experience high levels of disturbance, it is not clear whether the current arable weed flora is dominated by specialist or by generalist species and what would be the resulting variation in ecosystem function [23]. The present paper addresses this question and classifies the French arable weed flora along a specialist-generalist gradient, using vegetation records from a national monitoring network for applying and comparing six different specialisation indices available in the ecological literature. It should be noted here that what is meant by generalist species are species able to exploit many or all the niches within the "arable field" habitat regardless of their ability to occupy other habitats.

A second set of questions relates to possible relationships between the degree of specialisation of weed communities and disturbance regime that are related to the choice of contrasted agricultural management options. In this paper, we focus on two sets of situations that result in different levels and regime of disturbance.

The first situation compares the weed flora in maize cultivated as a monoculture and in a crop rotation. Monoculture means here that the same crop species is cultivated for several consecutive years. Crop rotation means that each year a different crop species is cultivated. Crop rotation induces disturbances that vary with the crop grown each year (planting or maturation dates, growth habit, competitive ability, associated cultural practices, fertiliser requirements and more or less specific herbicides) while the disturbance regime is constant in monocultures. While many recent studies focused on the impact of crop rotation on weed diversity [24-26], the present study aimed to quantify the functional shift in weed composition. There could be two alternative responses of weed communities to crop rotation (i) crop rotation could either favour generalist species and monoculture specialist species, or, (ii) crop rotation could favour specialist species of each crop (i.e., species that are associated with conditions of a particular crop), so that weed communities would mainly be composed of specialist species alternating each year, persisting within the seed bank during the unfavourable years.

The second situation analyses the shift in weed communities that has taken place in the same arable fields between the $1970 \mathrm{~s}$ and the $2000 \mathrm{~s}$. It is here assumed that the level of disturbance has significantly increased with agriculture intensification (i.e., increasing number of herbicide treatments, increasing depth and frequency of tillage, see [27]) between the two surveys. Increased $\mathrm{N}$-fertilization and systematic liming or drainage have homogenized soil conditions across the sampled fields. 
In addition, recurrent changes in cultivation techniques since the $1970 \mathrm{~s}$ (tillage or no-tillage systems, new herbicides) are likely to have translated into continuous environmental changes for the arable flora. These changes may have hampered specialist species and/or favoured generalist weed species.

\section{Results}

\section{Classification of weed species along the gradient of specialization}

In total, 152 weed species were frequent enough to estimate their degree of specialisation $\left(\mathrm{I}_{\mathrm{S}}\right)$ with six different indices (See additional file 1: Classification of arable weed species according to their niche breadth). Each pair of indices were significantly correlated (Table 1 ). The $\mathrm{I}_{\mathrm{S}}$ values varied from 15 for Stellaria media, the most generalist species, to 145 for Arenaria serpyllifolia, the most specialist species (Fig. 1). The segregation of the values of $I_{S}$ in three classes of equal size $(n=38$ species) enabled us to distinguish the most generalist species, from $I_{S}=15$ to $I_{S}=53$, intermediate species from $I_{S}=54$ to $I_{S}=92$ and the most specialist species, from $I_{S}=93$ to $I_{S}=145$. At the level of communities, the $I_{C S}$ values (i.e., the mean $I_{S}$ of the species present in the community) follow a normal distribution and varied from 14.33 to 102.58 (Fig. 2).

$\mathrm{I}_{\mathrm{S}}$ was negatively correlated with the frequency of occurrence of the species $(\mathrm{r}=-0.547 ; \mathrm{P}<0.001)$ but not significantly with their abundance $(\mathrm{r}=-0.132 ; \mathrm{P}=0.110)$ (Fig. 3). With the exception of Raphanus raphanistrum at $25 \%$ of its actual frequency, all six indices classified the species as generalists with very similar positions regardless of their rarefied frequency (Fig. 1).

The most generalist species (e.g. Stellaria media, Senecio vulgaris, Capsella bursa-pastoris, Anagallis arvensis) were found on a large range of soil types, climates, crop types and cropping techniques. In fact these species are found all over Western Europe [28], and even in other temperate countries such as Canada. At the opposite

Table 1 Spearman's rank correlation test between the six indices of species niche breadth

\begin{tabular}{lllllll}
\hline & $\begin{array}{l}\text { I1 } \\
\text { (RS) }\end{array}$ & $\begin{array}{l}\text { I2 (CCA- } \\
\text { SD) }\end{array}$ & $\begin{array}{l}\text { I3 (CCA- } \\
\text { Rao) }\end{array}$ & $\begin{array}{l}\text { I4 } \\
\text { (OMI) }\end{array}$ & I5 (IV) & $\begin{array}{l}\text { 16 } \\
\text { (Sophy) }\end{array}$ \\
\hline I1(RS) & 1 & $0.615^{* *}$ & $0,736^{* *}$ & $0,315^{* *}$ & $0,182^{*}$ & $0,692^{* *}$ \\
I2(CCA- & & 1 & $0.863^{* *}$ & $0.602^{* *}$ & $0.309^{* *}$ & $0.530^{* *}$ \\
SD) & & & & & & \\
I3(CCA- & & & 1 & $0.475^{* *}$ & $0.210^{* *}$ & $0.630^{* *}$ \\
Rao) & & & & & & \\
I4(OMI) & & & 1 & $0.260^{* *}$ & $0.226^{* *}$ \\
I5(IV) & & & & 1 & $0.153^{*}$ \\
I6(Sophy) & & & & & 1
\end{tabular}

Abbreviations: see Table 1. ${ }^{*} P<0.05 ;{ }^{*} P<0.01$

Note: correlations are based on $n=152$ weed species extreme, the most specialist species were weed species that all seemed highly specialized on at least two important axes of their n-dimensional niche, e.g., Rumex acetosella was only found in winter crops exhibiting very acidic and sandy soil conditions, while Phalaris paradoxa was only observed under rather oceanic climate, heavy clay and wet soil conditions. At an intermediary level, some species were specialized on one important axis of their niche while being present on a broader range of ecological conditions on other axes. For example, Papaver rhoeas or Veronica hederifolia were associated with a particular crop type (winter cereals) but were present on a large range of soil and climatic conditions while Juncus bufonius was strictly limited to acid and silty soils but was found in various crop types.

\section{Effect of monoculture versus crop rotation}

The comparison of maize weed communities in crop rotation versus monoculture showed similar field species richness or abundance (Table 2) while the average specialization index $\left(\mathrm{I}_{\mathrm{CS}}\right)$ indicated different species composition (Fig. 2). More generalist species were observed in fields with maize-wheat rotations $\left(\mathrm{I}_{\mathrm{CS}}=62+/-2\right)$, whereas maize monocultures contained more specialist species $\left(\mathrm{I}_{\mathrm{CS}}=69+/-1\right.$, Wilcoxon test, $\left.P<0.01\right)$. This was mainly due to the high proportion of generalist species when maize is grown in crop rotation (Table 2 ). The generalist Chenopodium album was the dominant species in both monoculture and crop rotation, followed by the two specialist species Echinochloa crus-galli and Amaranthus retroflexus in monocultures and the two generalist species Polygonum aviculare and Fallopia convolvulus in rotations. The two cropping systems were not evenly distributed between the different soil types, with proportionately more fields with crop rotation on clay soils and sandy clay soils, and more fields with monocultures on sandy soils (Table 3 ). However, the distribution of $I_{C S}$ values across soil types presented in Fig. 4 shows no significant effect of soil type on $I_{C S}$ of weed communities.

\section{Evolution of the specialist-generalist ratio over the last 30 years}

Between the $1970 \mathrm{~s}$ and the $2000 \mathrm{~s}$, weed species richness significantly decreased from 16.56 to 9.34 species per field and species density from 61.5 individuals per $\mathrm{m}^{2}$ to 20.2 (Table 2). Among the 121 species recorded in both surveys, 48 species significantly decreased in frequency and only 12 significantly increased.

The index of community specialization $\mathrm{I}_{\mathrm{CS}}$ significantly decreased from $\mathrm{I}_{\mathrm{CS}}=54.25+/-0.97$ in the $1970 \mathrm{~s}$ to $\mathrm{I}_{\mathrm{CS}}=$ $49.02+/-1.04$ in the $2000 \mathrm{~s}$ (Fig. 2, Wilcoxon-Test, $\mathrm{P}<$ $0.001)$. The frequency of generalist species was either stable (Capsella bursa-pastoris, Lolium multiflorum, Poa 


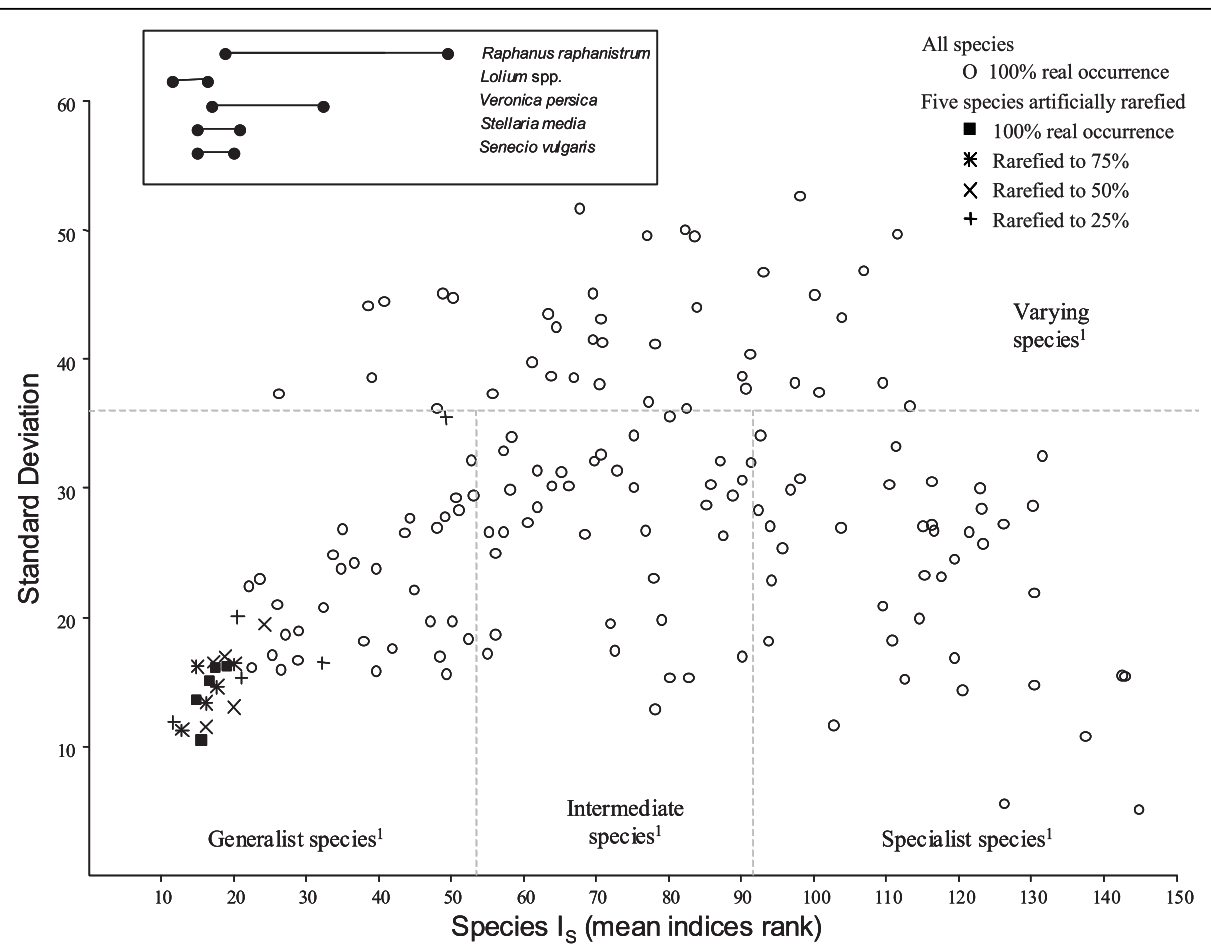

Figure 1 Weed species mean rank and standard deviation according to the six methods of classification along a specialist/generalist index. The mean rank and standard deviation of all weed species and for the 5 weed species artificially rarefied. The Y-axis gives the standard deviation of the mean value according to the 6 indices. The box gives the range of values for the five species. The full lists of the most generalist, intermediate, specialist and varying species are given in the Electronic Supplementary Material.

annua, Taraxacum officinale) or increased (Lactuca serriola, Senecio vulgaris), while the frequency of specialist species fell (Arenaria serpyllifolia, Lithospermum arvense, Legousia speculum-veneris, Stachys arvensis). There was a higher proportion of specialist species in the $1970 \mathrm{~s}$ while the weed communities of the $2000 \mathrm{~s}$ were characterized by a higher proportion of intermediate and generalist species, with $90 \%$ of the effect attributable to the loss of specialist species over time (Table 2).

\section{Discussion}

Robustness of the specialization index

The use of several indices was not to assess the performance and relative value of the different methods but rather to increase the robustness of the results. The six indices representing different measures of species niche breadth gave consistent and correlated classifications of species, from the most specialized to the most ubiquitous. Not surprisingly, there were exceptions, notably Plantago lanceolata, ranked according to I 2 as the most generalist species while the other five indices consistently classified this species as intermediate. Such differences presumably arose when species are regarded as generalist or not according to which niche axes were included in the analysis (e.g. soil, climate or crop type).
The significant correlations between the pairs of indices seem to indicate that the choice of an index based on species co-occurrence or on precise environmental data with different ordination or classification methods does not alter the ranking for most of the species. It is worth noting that indices based solely on species co-occurrence such as I6 demonstrated that increasingly available, large-survey datasets could yield information on species niche-breadth without detailed environmental or habitat measurements [29].

\section{Frequency and abundance of species according to their niche breadth}

The species with the largest niche breadth were also the most frequent but not necessarily the most abundant (Fig. 3). The random rarefaction of five common species in the dataset did not alter the classification of these species as generalists which tends to indicate that $\mathrm{I}_{\mathrm{S}}$ is not directly affected by the number of samples where the species concerned occurs (Fig. 1). This result partially supports the 'resource breadth hypothesis' [30] that states that 'species with broad environmental tolerance and able to use a wide variety of resources ('generalist species') would survive in more places and over larger areas'. It is however not clear to what extent the 


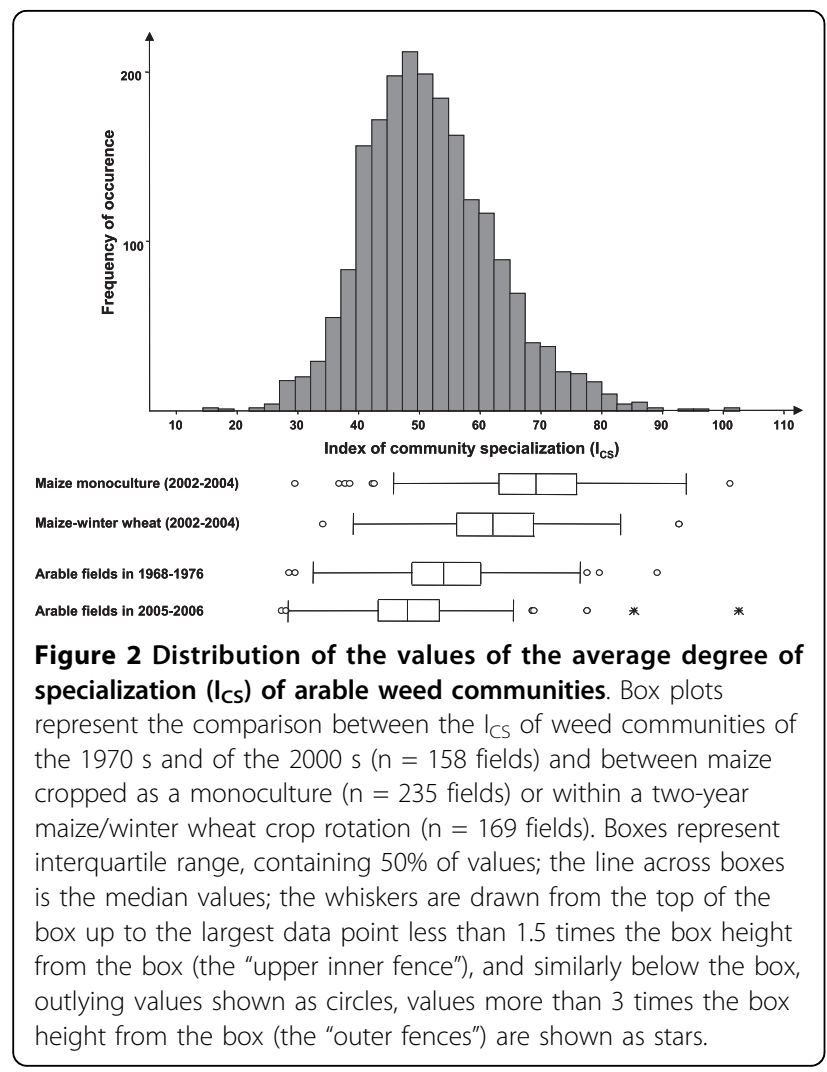

relationship could result from a sampling artefact, i.e. when data has been collected along a large environmental gradient, very frequent species will also appear as generalist species [31]. However, the reverse is not necessarily true: a rare species could either be generalist (if the rare sites where they occur are very different) or specialist (if all the sites where they occur have close ecological conditions and sufficient connectivity to be occupied). The absence of any strong relationships between niche breadth and species mean abundance means however that, contrary to the 'resource breadth hypothesis', not all generalist weed species would achieve high local densities. Moreover, the reverse seems often true in cultivated fields, since arable weeds that appear as specialists of a crop (for example Digitaria sanguinalis or Setaria pumila due to herbicide resistance in maize fields) can form very dense populations.

\section{The effect of disturbance dynamics on the assembly of communities}

We show here that a two-year cycle combining maize and winter wheat enhances the representation of generalist species in the weed communities found in maize (48\% of species) compared to maize cultivated as monoculture $(37 \%)$. Maize grown every two to three years does not appear to be sufficient in terms of (geometric)
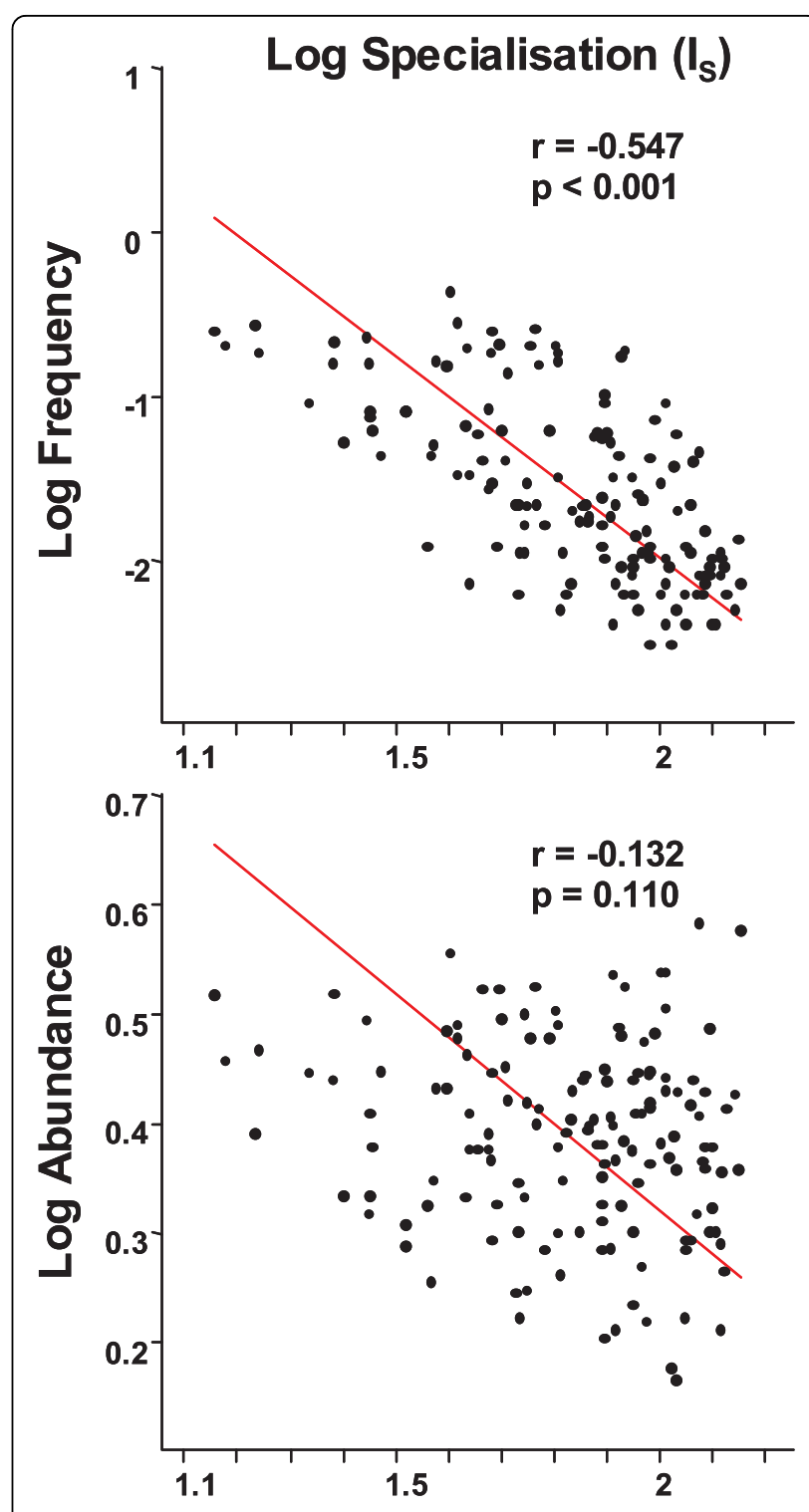

Figure 3 Relationships between weed species specialisation and (a) species frequency and (b) species local abundance. Note: correlations are based on $n=152$ plant species.

fitness advantage for specialist weed species to outperform the generalist species that are able to cope with alternating crops. Our results also suggest that in maize grown in a rotation, the annual change of crop sowing dates and associated practices have caused a shift in the weed flora in favour of 'germination generalist', i.e. species that can germinate all-year-round or at least in both autumn and spring (Polygonum aviculare, Lolium multiflorum, Alopecurus myosuroides, Anagallis arvensis, Galium aparine, Fumaria officinalis, Cirsium arvense and Viola arvensis) [32]. The annual changes in herbicide selectivity limit the selection of specialist species associated to a particular crop [33]. In the monoculture 
situation, although many generalist species were still observed, the repetition of a similar selection pressure each year appears to have favoured some of the efficient and well adapted species such as the intermediary-specialized Calystegia sepium, Cynodon dactylon, Amaranthus retroflexus or the specialized Digitaria sanguinalis, Datura stramonium or Setaria pumila species. It is worth noting that we found no significant differences in either weed diversity or weed density between crop rotation and monoculture which although counter-intuitive [24] is in line with several studies showing that the effect varies according to the rotation that is being considered [34,35]. As in the case of the present study, it is possible that the ratio of specialistgeneralist species in weed communities proves to be a more responsive indicator of the effect of monoculture versus crop rotation. This remains to be explored in further studies.

\section{Longer-term agricultural changes and the increasing proportion of generalist species}

The decline of arable weeds during the last decades has been reported in various European countries [36-38]. In this paper, we show that in addition to the loss in the number of species, the specialist-generalist ratio in weed communities has significantly changed over the last decades. This trend is mostly the result of a more pronounced decrease in the occurrence of specialist species, while during the same period intermediate and generalist species remained more often stable or even increased. For example, Legousia speculum-veneris and Lithospermum arvense are two specialist weeds of winter cereals on calcareous soils that are in decline most probably due to their sensitivity to the main herbicides used in cereals. The decline of Gnaphalium uliginosum, Misopates orontium and Stachys arvensis, specialist species of acidic and sandy soils, could be related to the agricultural practice of liming. Species of highly drained soils with poor competing capacity (like the specialist weed Arenaria serpyllifolia) could have been eliminated by an increased level of fertilization and the resulting increased competition with other plants, mostly the crop itself. On the other hand, the increase or the maintenance of species such as Senecio vulgaris, Matricaria perforata, Cirsium arvense, Poa annua or Lolium spp. can be explained in part by their generalist properties i. e. i) the capacity to germinate all year round and thus the possibility that some cohorts avoid herbicides pressures or periods of intense competition with the crop species, ii) the lack of specialisation to individual crop types and thus the lack of response to shifts in the acreage devoted to specific crops and iii) the tolerance to a broad range of soil types and thus the lack of response to changes in agricultural practices modifying ecological
Table 2 Mean species richness, abundance and ecological specialization of weed communities per field

\begin{tabular}{|c|c|c|c|c|c|c|}
\hline & \multicolumn{3}{|c|}{$\begin{array}{l}\text { a - Between } \\
\text { cropping systems }\end{array}$} & \multicolumn{3}{|c|}{ b - Over time } \\
\hline & Mo & Ro & $\mathbf{P}$ & $1970 \mathrm{~s}$ & $2000 \mathrm{~s}$ & $P$ \\
\hline \multicolumn{7}{|l|}{ Wilcoxon Test } \\
\hline Mean species richness & 12.59 & 14.06 & $\begin{array}{l}P= \\
0.07\end{array}$ & 16.56 & 9.34 & $\begin{array}{l}P< \\
0.01\end{array}$ \\
\hline Mean abundance & 9.56 & 8.11 & $\begin{array}{l}P= \\
0.07\end{array}$ & 61.5 & 20.2 & $\begin{array}{l}P< \\
0.01\end{array}$ \\
\hline Khi2 Test & \multicolumn{2}{|c|}{ Khi2 $=84.5$} & $\begin{array}{l}P< \\
0.01\end{array}$ & \multicolumn{2}{|c|}{ Khi2 $=64.0$} & $\begin{array}{l}P< \\
0.01\end{array}$ \\
\hline
\end{tabular}

Sum of occurrences

for:

$\begin{array}{lllll}\text { Generalist species } & 1129 & 1154 & 2180 & 135\end{array}$

Intermediate species $\quad 777 \quad 485 \quad 676 \quad 405$

Specialist species $\quad 429 \quad 268 \quad 344 \quad 99$

Total $2959 \quad 2377 \quad 3200 \quad 1885$

a- in maize fields cultivated as monoculture $(M o, n=235)$ and in maize-wheat rotations ( $\mathrm{Ro}, \mathrm{n}=169$ ) in the $2000 \mathrm{~s}$,

b- for the same fields over time between the $1970 \mathrm{~s}$ and the $2000 \mathrm{~s}$ ( $\mathrm{n}=158$ fields).

conditions (fertilization, liming, drainage, irrigation). Our results therefore indicate that not only did agroecosystems lose a significant number of weed species in the recent decades, but those that remain also are the most generalist, which could lead to a decreased differentiation of weed communities found in different crop types in the longer term. This confirms that the biotic homogenisation process reported in other plant groups in rural landscapes [16] also affects weed communities found in cultivated fields.

There may be an apparent contradiction in the results between the selection of generalists over the last 30 years of agricultural intensification and the selection of specialists by monocultures (which is also perceived as part of the intensification process). However, this paradox disappears when analyzing the nature of the species specialization in each situation. In the diachronic long term study, the ratio of generalist/specialist increases

Table 3 Distribution of cropping system according to soil types

\begin{tabular}{llll}
\hline Soil types (texture) & Monoculture & Crop rotation & Total \\
\hline Clay & 16 & 15 & 31 \\
Clay loam & 36 & 21 & 57 \\
Sandy clay & 7 & 9 & 16 \\
Silt loam & 25 & 13 & 38 \\
Silty clay & 12 & 10 & 22 \\
Sandy loam & 9 & 7 & 16 \\
Sand & 44 & 4 & 48 \\
\hline Total & 150 & 78 & 228 \\
\hline
\end{tabular}

Khi2 Test, Khi2 $=22.4, \mathrm{P}<0.005$ 


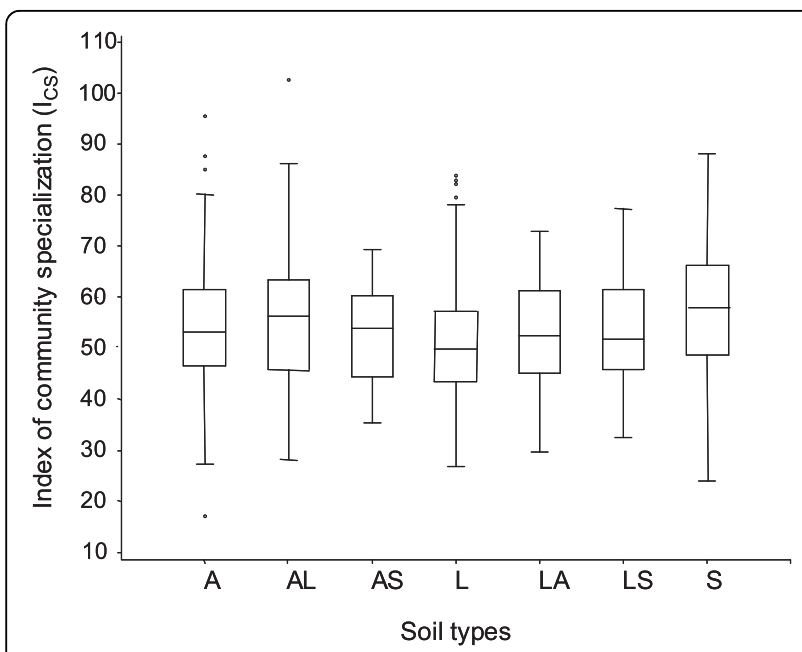

Figure 4 Distribution of $\mathrm{I}_{\mathrm{CS}}$ values in maize fields according to soil types. Note: $\mathrm{n}=404$ fields i.e. 235 cropped as monoculture and 169 as crop rotation; A: clay; AL: clay loam; AS: sandy clay; L: silt loam; LA: silty clay; LS: sandy loam; S: sand.

because a lot of specialist species of typical physical environments have disappeared or decreased with the concomitant decline or extinction of their preferred niche within arable fields (i.e. species adapted to nutrient poor soils, either wet and sandy soil or calcareous rocky and dry soils). The difference of $\mathrm{I}_{\mathrm{CS}}$ in weed communities found in crop rotation and in monoculture is more related to the specialization of species to the crop species, and more specifically to the crop germination date. In our study, species that were specialist of specific crops could generally grow on a wide range of soil and climatic conditions, for example Amaranthus retroflexus and Digitaria sanguinalis which grow in maize crops.

\section{Conclusions}

This study aimed to classify arable weeds along a generalist/specialist continuum and to assess if differences in disturbance patterns could lead to differences in the representation of generalist and specialist species in plant communities. Our study extends ecological approaches to an environment highly disturbed by human activities where it is not often easy to get clear expectations between contrasted and/or opposite forces that govern the assembly of community. The distinction of species into generalist or specialist species helps to highlight the general rules in the assembly of weed species into communities [39]. In our case, the classification of 152 arable weed species along a specialist/generalist gradient gives insights to their contrasted responses to changes in agriculture. We show that the relative proportion of generalist and specialist species is not constant but varies in relation to the frequency and intensity of disturbance that result from agricultural practices. Our results also show that, despite the high level of disturbance that characterises agroecosystems, ecological theories developed in more stable environments do apply and that either a sequence of disturbances of different nature (crop rotation) and/or the intensification of disturbances have favoured the most generalist species.

\section{Methods}

\section{Weed flora and environmental data}

We used plots data derived from Biovigilance Flore, a national monitoring scheme designed to survey changes in arable flora in relation to farming practices [40]. In the centre of 724 cultivated fields selected to cover the diversity of cultural techniques and environmental conditions occurring in annual crop fields throughout mainland France, comprehensive vegetation records were carried out in two separate $2000 \mathrm{~m}^{2}$ plots, i.e. one sprayed with herbicides and a second located in an unsprayed control area. The 'herbicide' and the 'control' plots were randomly placed within the field, at least 20 $\mathrm{m}$ from the edge. The control plot is subjected to all cultivation practices but the herbicide treatments. Vegetation was recorded over the whole $2000 \mathrm{~m}^{2}$, twice a year, the first survey about a month after crop sowing and the second later on during crop development, i.e. early April for winter-sown crops and early July for spring and summer-sown crops. This sampling design provided a total of 2896 plots between 2002 and 2004 . The abundance of each species was estimated using six abundance classes: ' + ' found once in the $2000 \mathrm{~m}^{2}$ area; ' 1 ' less than 1 individual $/ \mathrm{m}^{2}$; ' 2 ' $1-2$ individual $/ \mathrm{m}^{2}$; ' 3 ' 3 20 individuals $/ \mathrm{m}^{2}$; ' 4 ' $21-50$ individuals $/ \mathrm{m}^{2}$; ' 5 ' more than 50 individuals $/ \mathrm{m}^{2}$ (for further sampling details, see [20]). In parallel to vegetation sampling, the monitoring scheme included the record of environmental variables as well as a survey describing agricultural practices collected by an interview with the farmers (Table 4). These were available for 694 out of the initial 724 fields. In this study, we extracted variables that are known to affect weed species distribution $[19,20]$. These included environmental variables such as altitude, climatic conditions (maximal and minimal temperature, total rainfall and evapotranspiration) derived from METEO-France climatic data with the AURELHY method of interpolation [41], soil texture (7 classes) and soil pH. Relevant agronomic variables were the crop rotation history, sowing date and tillage operations (type and number of operations, maximum depth of tillage). Precise data about herbicides, fertilizer levels and crop canopy were not available for all fields so are not included.

\section{Niche breadth indices}

The degree of specialisation of individual species was computed using six different published methods, since none of 
them has received unanimous preference (Table 4) [42]. $\mathrm{I}_{1}$ and $\mathrm{I}_{6}$ were calculated solely on vegetation data and were estimated using the 2896 plot data. The other four indices were derived from both the environmental and agronomical variables described above and vegetation data which was pooled at the field level $(n=694)$. For indices $I_{2}$ to $I_{5}$, we pooled the floristic data of the herbicides plots and the unsprayed control plots as preliminary tests performed on each dataset independently indicated no significant differences in species ranking.

Indices $I_{1}$ to $I_{4}$ use multivariate space to estimate niche breadth and relative position. In these analyses, a generalist species would cover a large volume of the n-dimensional ordination space, while a specialist species would be confined in a restricted area of that same ordination space (Fig. 5). Index $\mathrm{I}_{1}$ uses the method of 'Reciprocal scaling' which is based on the Correspondence Analysis of a species-sample matrix [43]. Indices $\mathrm{I}_{2}$ and $\mathrm{I}_{3}$ use Canonical Correspondence Analysis (CCA) as originally developed to discriminate species niches along environmental gradients. To measure the dispersion of the samples occupied by a species, Index $\mathrm{I}_{2}$ uses the standard deviation of species score in CCA [44] while Index $\mathrm{I}_{3}$ is based on the metrics of Rao $[45,46]$ as proposed by Thioulouse et al. [47]. Indices $\mathrm{I}_{1}$ to $\mathrm{I}_{3}$ assume unimodal response curves of species to environmental gradients, while Index $\mathrm{I}_{4}$, the Outlying Mean Index (OMI) analysis makes no assumption about the shape of species response curves to the environment and, unlike CCA used in indices $\mathrm{I}_{2}$ and $\mathrm{I}_{3}$, Index $\mathrm{I}_{4}$ gives equal weight to species-rich and species-poor sites [48].

Index $\mathrm{I}_{5}$ uses the IndVal procedure [49] primarily designed to target indicator species according to ecological conditions using cluster analysis. It can also be used to distinguish generalist from specialist species [50], the most generalist species being associated with a broad partition while the most specialist species are associated with finer partitions i.e. clustered latter in the ordination tree.
Index $\mathrm{I}_{6}$ was based solely on the information given by species co-occurrence and assumed the principle that, all else being equal, generalists co-occur with many species across their range, while specialists co-occur with relatively few species [51]. Contrary to simple distance measures based on compositional dissimilarity, the distance between samples computed with index $I_{6}$ is weighted by the ecological distance between the species with more weight given to species that are found under different conditions and less weight to species that are found under the same conditions, as detailed hereafter. First, the frequency of co-occurrence (F) between each pair of species was computed, where $\mathrm{F}(a / b)$ is the probability to find species $a$ when species $b$ is present (in general, $\mathrm{F}(a, b)$ is different from $\mathrm{F}(b, a))$. The same kind of relationship can then be computed between a sample $(\mathrm{S})$ and a species $(a)$, the sample being considered as the mean of the species it contains:

$$
\mathrm{F}(\mathrm{S}, a)=[\mathrm{F}(\mathrm{x} 1, a)+\mathrm{F}(\mathrm{x} 2, a)+\ldots+\mathrm{F}(\mathrm{xi}, a)+\ldots+\mathrm{F}(\mathrm{xn}, a)] / \mathrm{n}
$$

with $\mathrm{x} 1$ to $\mathrm{xn}, \mathrm{n}$ species present in the sample $\mathrm{S}$. Hence, the distance between each pair of samples depends not only on their respective composition but also on a common global reference, i.e., the entire complement of species within the data set. Therefore even samples with no common species can be compared (i.e. their distance will not systematically equals 1 ) and the measure is independent of species richness in the samples.

\section{Classification of the French arable flora along a specialist- generalist gradient}

For each index, we ranked all the species observed in at least ten fields from the most generalist (rank 1) to the most specialist species (rank n). Spearman's rank correlation test was then used to compare the classifications given by each index. For each species, we calculated the mean rank and standard deviation over the six indices.

Table 4 Methods, references and data used to compute the six species habitat breadth indices and species niche position index

\begin{tabular}{|c|c|c|c|}
\hline Method and reference & Applications to plant communities & \# of plots & Habitat variables \\
\hline$I_{1}$ (RS) Reciprocal scaling [43] & [53] & $2896 *$ & None \\
\hline $\mathrm{I}_{2}$ (CCA-SD) Canonical Correspondence Analysis [44] & [54] & 694 & See list $* *$ \\
\hline $\mathbf{I}_{3}$ (CCA-Rao) Canonical Correspondence Analysis [47] based on $[45,46]$ & - & 694 & See list ** \\
\hline $\mathbf{I}_{\mathbf{4}}$ (OMI) Outlying Mean Index analysis [48] & [55] & 694 & See list ** \\
\hline$I_{5}$ (IV) IndVal [49] & [50] & 694 & See list $* *$ \\
\hline $\mathrm{I}_{6}$ (Sophy) Species mean socio-ecological distances [51] & [51] & $2896 *$ & None \\
\hline
\end{tabular}

$2896 * 724$ fields with 2 plots surveyed twice a year

List ** includes habitat variables: Altitude, Mean temperature, Total rainfall, Evapotranspiration, Soil pH, Soil texture, Crop, Preceding crop, Sowing date, Tillage system and Tillage depth.

Tillage system: no-tillage (i.e. implementing direct drilling), minimum tillage which consists in only chiselling the soil and conventional tillage including tilling the soil with mouldboard plough followed by one or more harrow and/or cover-crops passage(s). 


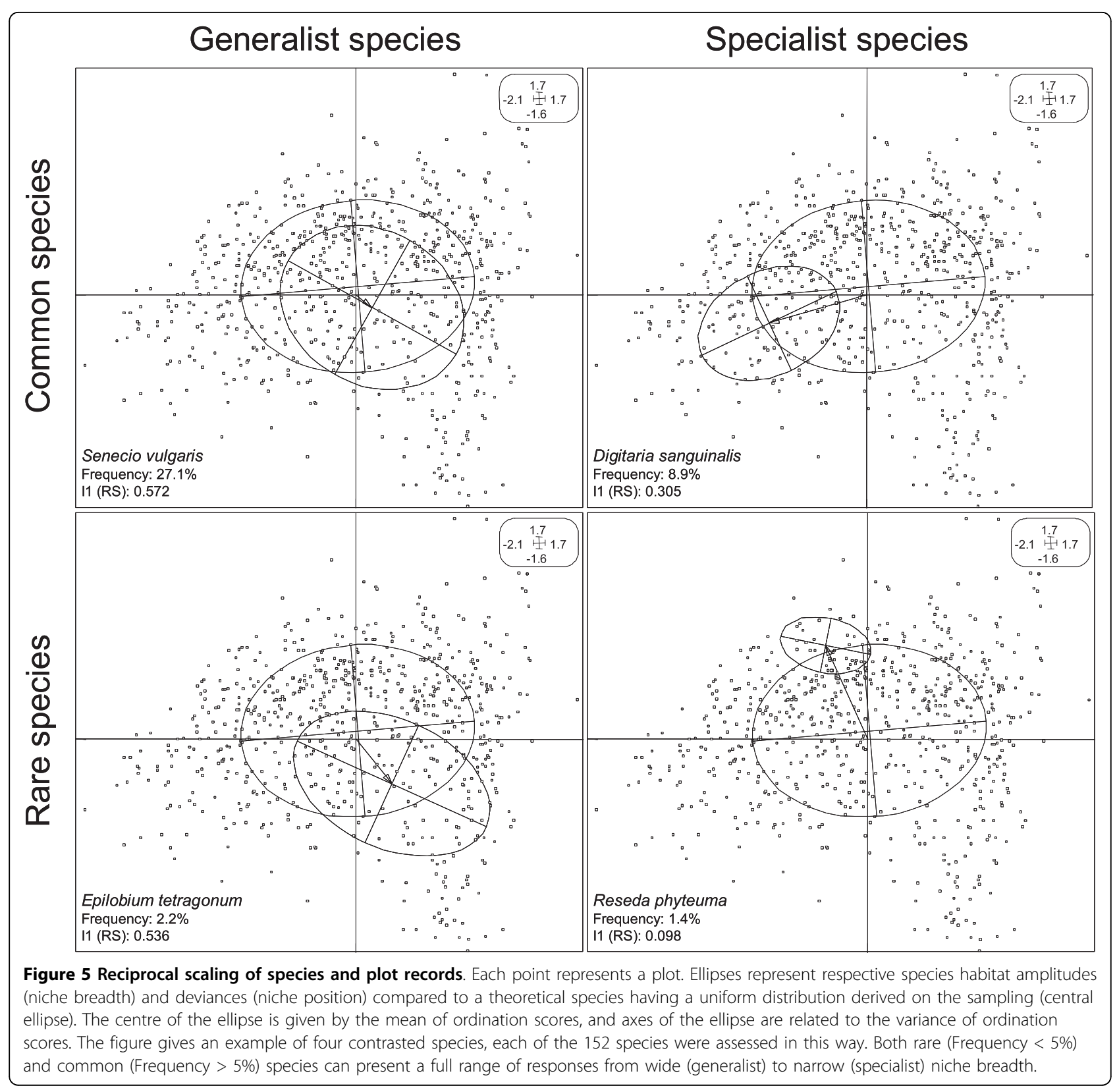

The mean rank resulted in a global index of specialization $\left(\mathrm{I}_{\mathrm{S}}\right)$; low $\mathrm{I}_{\mathrm{S}}$ indicated generalist species whereas high Is indicated specialist species. We cut the continuum of $\mathrm{I}_{\mathrm{S}}$ into three classes of equal size to classify species as either generalist, intermediate or specialist. The $25 \%$ species having the highest $\mathrm{I}_{\mathrm{S}}$ standard deviation were grouped into a fourth category called "varying category". Finally, we randomly rarefied 5 species (Lolium multiflorum, Raphanus raphanistrum, Senecio vulgaris, Stellaria media and Veronica persica) to $75 \%, 50 \%$ and $25 \%$ of their real occurrences in order to check for a frequency-dependence bias in our classification.
Finally, we computed the frequency and abundance of each species. The frequency is the number of occurrences where the species is present divided by the total number of surveyed plots while the mean abundance is given by the following formula:

$$
\text { Mean abundance }=11.5 * \mathrm{n} 3+35.5 * \mathrm{n} 4+75.5 * \mathrm{n} 5+1.5(\mathrm{~N}-\mathrm{n} 3-\mathrm{n} 4-\mathrm{n} 5) / \mathrm{N}
$$

with $\mathrm{n} 3, \mathrm{n} 4, \mathrm{n} 5$ the number of samples within the coefficients classes 3,4 and 5 respectively and $\mathrm{N}$, the total number of samples. 11.5, 35.5 and 75.5 correspond to the mean plant * $\mathrm{m}^{-2}$ density of the abundance coefficient classes 3,4 and 5 , respectively [52]. 


\section{Community response to disturbance regimes in agricultural systems}

The average degree of specialization of a given community $\mathrm{I}_{\mathrm{CS}}$ was calculated as the mean $\mathrm{I}_{\mathrm{S}}$ of the species present. Species belonging to the 'varying category' were not used in the $\mathrm{I}_{\mathrm{CS}}$ calculations. As differences in $\mathrm{I}_{\mathrm{CS}}$ between communities could either reflect (i) a difference in the proportion of generalist species in the community, (ii) a difference in the proportion of specialists or (iii) a combination of both, we used the proportion of specialist, intermediate and generalist species in the community as additional indicators.

The comparison of weed communities in monoculture versus crop rotation was based on data from the Biovigilance Flore dataset. We used vegetation plots sampled in maize cultivated in monoculture for at least the last four years ( $\mathrm{n}=235$ fields) and vegetation plots recorded in maize fields cropped within a crop-rotation just after winter wheat ( $\mathrm{n}=169$ fields). We compared $\mathrm{I}_{\mathrm{CS}}$ in monoculture and crop rotation using a Wilcoxon test and the proportion of generalist, intermediate and specialist species using a $\chi^{2}$-test. To ensure that the influence of soil type on the $\mathrm{I}_{\mathrm{CS}}$ index is not confounding the analysis of the cropping systems, we have analysed the distribution of cropping systems as well as the distribution of $\mathrm{I}_{\mathrm{CS}}$ values across soil types.

The comparison of weed communities occurring in the $1970 \mathrm{~s}$ and in the $2000 \mathrm{~s}$ was carried out by using a repeat survey (2005-2006) of 158 fields initially surveyed between 1968 and 1976 (for further sampling details, see [38]). $I_{C S}$ and the proportion of species belonging to the three classes were compared as described above.

\section{Additional material}

Additional file 1: Classification of arable weed species according to their niche breadth. Additional file descriptions text (including details of how to view the file, if it is in a non-standard format). The file is in PDF format. It gives a table with the mean degree of specialisation $\left(I_{S}\right)$ of 152 weed species according to the score given by six different niche breadth indices that are also given in the table.

\footnotetext{
Acknowledgements

The authors wish to thank all the people involved in the French weed monitoring network 'Biovigilance Flore' for providing data, as well as Gilbert Barralis for conducting the first regional weed survey. The current field survey has been financed by the French Ministry of Agriculture. Guillaume Fried has benefited from a 'Formation Complémentaire Par la Recherche' fellowship from the French Ministry of Agriculture. The study has been partly granted by the ANR-OGM VigiWeed project. The helpful suggestions and insights emerging from the critical review by Wilfried Thuiller from LECA, Martin J. Lechowicz from McGill University and Sabrina Gaba from INRA Dijon were gratefully appreciated. We thank Jean-Luc Demizieux for improving our manuscript. We are also grateful to Les Firbank for providing useful scientific suggestions and improving the grammatical quality of the manuscript. This research was conducted in accordance with the laws of France.
}

\section{Author details}

${ }^{1}$ INRA, UMR1210 Biologie et Gestion des Adventices, F-21000 Dijon, France. 'LNPV, Station d'Entomologie et Plantes Invasives, F-34000 Montpellier, France.

\section{Authors' contributions}

GF collected the data, carried out the analysis and drafted the manuscript. $X R$ was at the initiative of the project and supervised its development and funding. SP helped develop the theoretical background and assisted in drafting and revised the manuscript. All authors read and approved the final manuscript.

Received: 2 October 2009 Accepted: 1 September 2010

Published: 1 September 2010

\section{References}

1. Hutchinson GE: Concluding remarks. Cold Spring Harbor Sym 1957, 22:415-427.

2. Colwell RK, Futuyma DJ: On the Measurement of Niche Breadth and Overlap. Ecology 1971, 52:567-576.

3. Petraitis PS: Likelihood Measures of Niche Breadth and Overlap. Ecology 1979, 60:703-710.

4. Smith EP: Niche Breadth, Resource Availability, and Inference. Ecology 1982, 63:1675-1681.

5. Levins R: Theory of fitness in a heterogeneous environment. I. The fitness set and adaptive function. Am Nat 1962, 96:361-373.

6. MacArthur RH: Geographical Ecology New York, USA: Harper \& Row 1972.

7. Futuyma DJ, Moreno G: The evolution of ecological specialisation. Annu Rev Ecol Syst 1988, 19:207-233.

8. Kawecki TJ: Accumulation of deleterious mutations and the evolutionary cost of being a generalist. Am Nat 1994, 144::833-838.

9. Southwood TRE: Habitat, the templet for ecological strategies? J Anim Ecol 1977, 46:337-365.

10. Brouat C, Chevallier H, Meusnier S, Noblecourt T, Rasplus J-Y: Specialization and habitat: spatial and environmental effects on abundance and genetic diversity of forest generalist and specialist Carabus species. Mol Ecol 2004, 13:1815-1826.

11. Sol D, Timmermans $S$, Lefebvre L: Behavioural flexibility and invasion success in birds. Anim Behav 2002, 63:495-502.

12. Dall SRX, Cuthill IC: The information costs of generalism. Oikos 1997 , 80:197-202.

13. Weiher $E$, Keddy PA: Assembly rules as general constraints on community composition. In Ecological Assembly Rules: Perspectives, Advances, Retreats. Edited by: Weiher E, Keddy PA. Cambridge University Press, Cambridge; 1999:251-271.

14. Scott MC, Helfman GS: Native invasions, homogenization, and the mismeasure of integrity of fish assemblages. Fisheries 2001, 26:6-15.

15. Devictor $V$, Julliard $R$, Couvet $D$, Lee $A$, Jiguet F: Functional Homogenization Effect of Urbanization on Bird Communities. Conserv Biol 2007, 21:741-751.

16. Smart SM, Thompson K, Marrs RH, Le Duc MG, Maskell LC, Firbank LG Biotic homogenization and changes in species diversity across humanmodified ecosystems. P Royal Soc B 2006, 273:2659-2665.

17. Mackinney ML, Lockwood JL: Biotic homogenization: a few winners replacing many losers in the next mass extinction. Trends Ecol Evol 1999, 14:450-453.

18. Bowers MA, Harris LC: A large-scale metapopulation model of interspecific competition and environmental-change. Ecol Model 1994 72:251-273.

19. Lososova Z, Chytry M, Cimalova S, Kropac Z, Otypkova Z, Pysek P, Tichy L: Weed vegetation of arable land in Central Europe: Gradients of diversity and species composition. J Veg Sci 2004, 15:415-422.

20. Fried $G$, Norton $L R$, Reboud $X$ : Environmental and management factors determining weed species composition and diversity in France. Agr Ecosyst Environ 2008, 128:68-76

21. Bisang I, Bergamini A, Lienhard L: Environmental-friendly farming in Switzerland is not hornwort-friendly. Biol Cons 2009, 142:2104-2113.

22. Firbank LG: Short-term variability of plant populations within a regularly disturbed habitat. Oecologia 1993, 94:351-355. 
23. Lavorel S, Garnier E: Predicting changes in community composition and ecosystem functioning from plant traits: revisiting the Holy Grail. Funct Ecol 2002, 16:545-556

24. Legère $A$, Stevenson $F C$, Benoit DL: Diversity and assembly of weed communities: contrasting responses across cropping systems. Weed Res 2005, 45:303-315.

25. Smith RG, Gross KL: Assembly of weed communities along a crop diversity gradient. J Appl Ecol 2007, 44:046-1056.

26. Ulber L, Steinmann HH, Klimek S, Isselstein J: An on-farm approach to investigate the impact of diversified crop rotations on weed species richness and composition in winter wheat. Weed Research 2009, 49:534-543.

27. Stoate C, Boatman ND, Borralho RJ, Rio Carvalho C, de Snoo GR, Eden P. Ecological impacts of arable intensification in Europe. Journal of Env Man 2001, 63:337-365.

28. Schroeder D, Mueller-Schaerer $H$, Stinson CSA: A European weed survey in 10 major crop systems to identify targets for biological control. Weed Res 1993, 33:449-458.

29. Fridley JD, Vandermast DB, Kuppinger DM, Manthey M, Peet RK: Cooccurrence based assessment of habitat generalists and specialists: a new approach for the measurement of niche width. J Ecology 2007, 95:707-722.

30. Brown $\mathrm{JH}$ : On the relationship between abundance and distribution of species. Am Nat 1984, 124:255-279.

31. Gaston KJ, Spicer IJ: The relationship between range size and niche breadth: a test using five species of Gammarus (Amphipoda). Global Ecol Biogeogr 2001, 10:179-188.

32. Andersson TN, Milberg P: Weed flora and the relative importance of site, crop, crop rotation, and nitrogen. Weed Sci 1998, 46:30-38

33. Fried G, Chauvel B, Reboud X: A functional analysis of large-scale temporal shifts from 1970 to 2000 in weed assemblages of sunflower crops in France. J Veg Sci 2009, 20:49-58.

34. Stevenson FC, Legere A, Simard RR, Angers DA, Pageau D, Lafond J: Weed species diversity in spring barley varies with crop rotation and tillage, but not with nutrient source. Weed Sci 1997, 45:798-806.

35. Légère A, Derksen DA: Is Diversity a Useful Concept for Weed Management? Xlième Colloque International sur la Biologie des Mauvaises Herbes 2000, 407-410.

36. Andreasen C, Stryhn H, Streibig JC: Decline of the flora in Danish arable fields. J Appl Ecol 1996, 33:619-626.

37. Baessler C, Klotz S: Effects of changes in agricultural land-use on landscape structure and arable weed vegetation over the last 50 years. Agr Ecosyst Environ 2006, 115:43-50.

38. Fried G, Petit S, Dessaint F, Reboud X: Arable weed decline in Northern France: crop edges as refugia for weed conservation? Biol Cons 2009, 142:238-243.

39. Booth BD, Swanton CJ: Assembly theory applied to weed communities. Weed Sci 2002, 50:2-13.

40. Fried G, Reboud X, Gasquez J, Delos M: Le réseau « Biovigilance Flore »: Présentation du dispositif et première synthèse des résultats. Vingtième conférence du Columa. Journées internationales sur la lutte contre les mauvaises herbes Dijon, France 2007, 315-325.

41. Benichou $P$, Lebreton O: Prise en compte de la topographie pour la cartographie des champs pluviométriques statistiques. La Météorologie 1987, 7:23-34

42. Austin MP: Spatial prediction of species distribution: an interface between ecological theory and statistical modelling. Ecol Model 2002, 157:101-118

43. Thioulouse J, Chessel D: A method for reciprocal scaling of species tolerance and sample diversity. Ecology 1992, 73:670-680.

44. Shenbrot Gl, Rogovin KA, Surov AV: Comparative analysis of spatia organization of desert lizard communities in Middle Asia and Mexico. Oikos 1991, 61:157-168.

45. Rao CR: Diversity and dissimilarity coefficients: a unified approach. Theor Popul Biol 1982, 21:24-43.

46. Rao CR: Rao's axiomatization of diversity measures. In Encyclopedia of Statistical Sciences. Edited by: Kotz S, Johnson NL. New York: Wiley; 1986:614-617

47. Thioulouse J, Chessel D, Dolédec S, Olivier JM: ADE-4: a multivariate analysis and graphical display software. Stat Comput 1997, 7:75-83.
48. Dolédec S, Chessel D, Gimaret-Carpentier C: Niche separation in communty analysis: a new method. Ecology 2000, 81:2914-2927.

49. Dufrêne $M$, Legendre $P$ : Species assemblages and indicator species: the need for a flexible asymmetrical approach. Ecol Monogr 1997, 67:345-366.

50. Devineau JL: Generalist versus specialist: a contrasted sociology of woody and herbaceous species in a fallow-land rotation system in the West African savanna (Bondoukuy, Western Burkina Faso). Phytocoenologia 2005, 35:53-77.

51. Brisse H, de Ruffray $P$, Grandjouan G, Hoff M: The phytosociological database 'SOPHY'. Part I: Calibration of indicator plants. Part II: Socioecological classification of the relevés. European vegetation survey. Annali di Botanica 1995, 53:177-223.

52. Barralis G: Répartition et densité des principales mauvaises herbes en France Paris: INRA - AFPP 1977.

53. Alard D, Poudevigne I: Factors controlling plant diversity in a rural landscape: a functional approach. Landscape and Urban Plan 1999, 46:29-39.

54. Gregory RD, Gaston KJ: Explanations of commonness and rarity in British breeding birds: separating resource use and resource availability. Oikos 2000, 88:515-526.

55. Thuiller W, Lavorel S, Midgley G, Lavergne S, Rebelo T: Relating plant traits and species distributions along bioclimatic gradients for 88 Leucadendron taxa. Ecology 2004, 85:1688-1699.

doi:10.1186/1472-6785-10-20

Cite this article as: Fried et al:: A specialist-generalist classification of the arable flora and its response to changes in agricultural practices. BMC Ecology 2010 10:20.

\section{Submit your next manuscript to BioMed Central and take full advantage of:}

- Convenient online submission

- Thorough peer review

- No space constraints or color figure charges

- Immediate publication on acceptance

- Inclusion in PubMed, CAS, Scopus and Google Scholar

- Research which is freely available for redistribution

Submit your manuscript at www.biomedcentral.com/submit
C) Biomed Central 